\title{
Broken chain of treatment as an independent prognostic factor affecting survival after autologous stem cell transplantation for relapsed or refractory Hodgkin lymphoma
}

SHilo P.S. ${ }^{1}$, Alekseev S.M. ${ }^{1}$, Zyuzgin I.S. ${ }^{1}$, Ishmatova I.V. ${ }^{1}$, Motalkina M.S. ${ }^{1}$, Harchenko E.V. ${ }^{1}$, CHudinovskih YU.A. ${ }^{1}$, Subora A.YU. ${ }^{1}$, SHalaev S.A. ${ }^{1}$, OlejnikYU.A. ${ }^{1}$, Milovidova S.A. ${ }^{1}$, Kuleva S.A. ${ }^{1}$, Filatova L.V. ${ }^{1}$, Semiglazova T.YU. ${ }^{1}$

${ }^{1}$ N.N. Petrov Research Institute of Oncology, Saint-Petersburg, Russia

\section{INTRODUCTION}

High dose chemotherapy with autologous stem cell transplantation (ASCT) is a standart of treatment for eligible patients with relapsed or refractory Hodgkin lymphoma (HL), providing long-term disease-free survival in over $50 \%$ of patients. There are a large number of studies investigating risk factors for survival after ASCT, but none of them assess the lack of timely mannered qualified medical care as potential risk factor together with those already studied. The insufficient number of Russian medical centers which Insufficient HIDT with ASCT, results into a brich can provide HDCT with ASCT, results into a broke chain of treatment. The main goal of this thesis is the evaluation of a timely mannered qualified medica help as potential independent prognostic factor, and assessing it's impact into survival rate.

\section{PATIENTS AND METHODS}

Our study included data of 96 patients with refractory or relapsed $\mathrm{HL}$ who underwent treatment between 2013 and 2018 in single center. Prognostic model for PFS after ASCT was performed from univariate and multivariate analysis of 18 potential risk factors. The primary endpoint was PFS defined as the interval between ASCT and the earliest date of the progression of $\mathrm{HL}$ relapse of $\mathrm{HL}$ or death from any cause. By the " therm "chan beginning of salvage therapy outside of federa medical institution with the possibility of performing ASCT.

\section{RESULTS}

In univariate analysis we identified nine potential negative prognostic factors which were included into multivariate analysis. 2-year PFS rate was also evaluated.

Due to our data, the independent negative prognostic factors affecting progression-free survival are:

disease status prior ASCT less than CR (23\% vs 58\%; HR 2,1 [95\% Cl 1.20-3.56], $p=0.009)$

presence of chain treatment disruption (34\% vs 50\%; HR 2,9 [95\% Cl 2.43-4.2], $\mathrm{p}=0.029$ ),

- primary-refractory disease ( $29 \%$ vs $77 \%$; HR 2,1 [95\% Cl 1.2-3.56], $\mathrm{p}=0.041$ ).

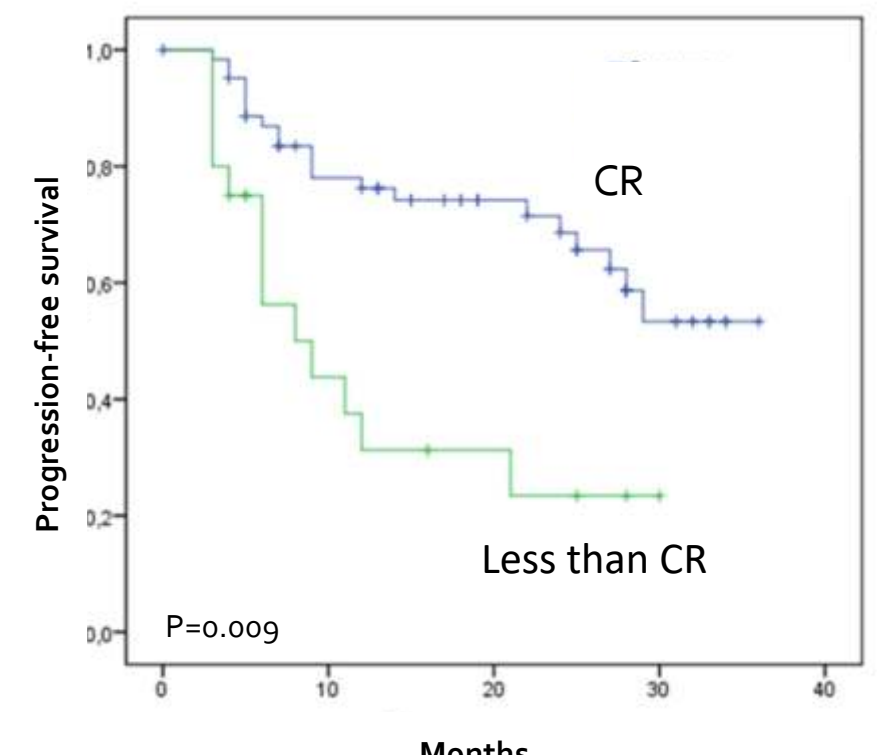

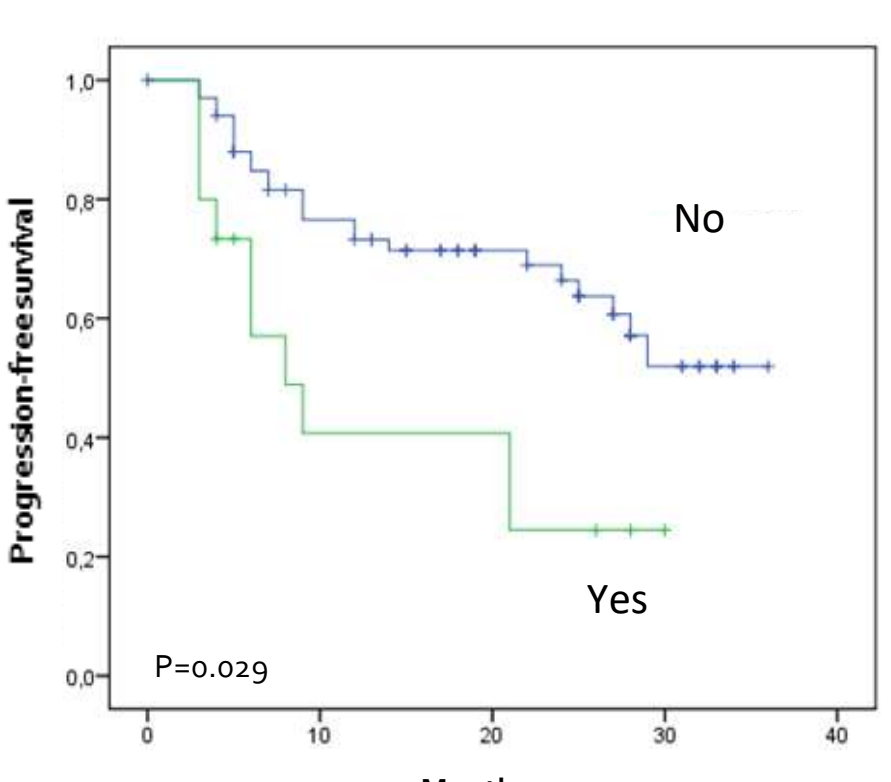

Months
Figure 2. Presence of chain treatment disruption

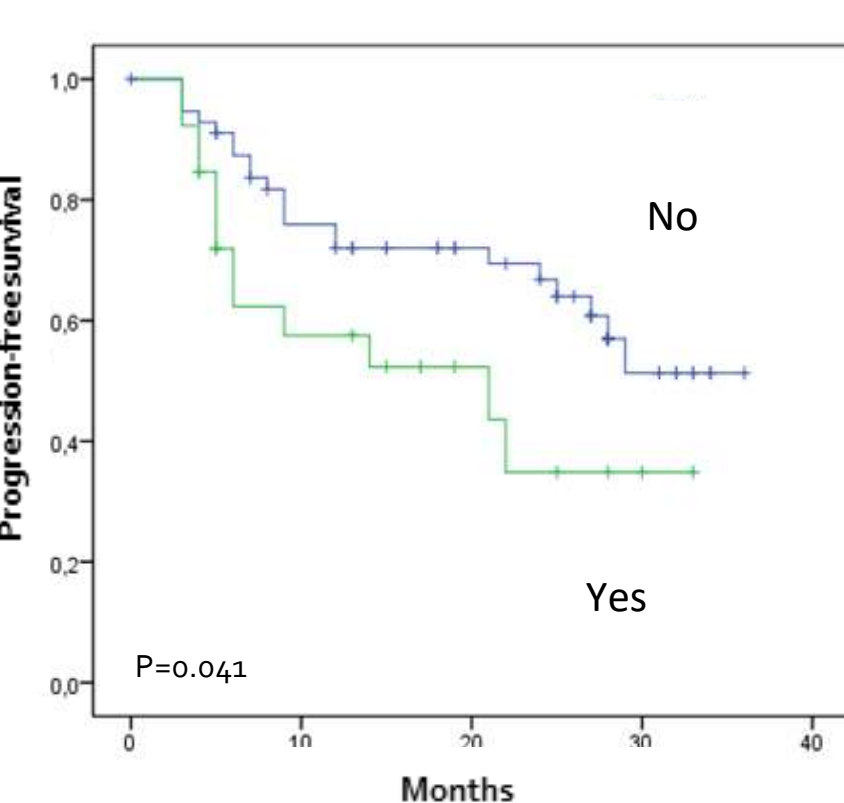

Figure 3. Primary-refractory disease

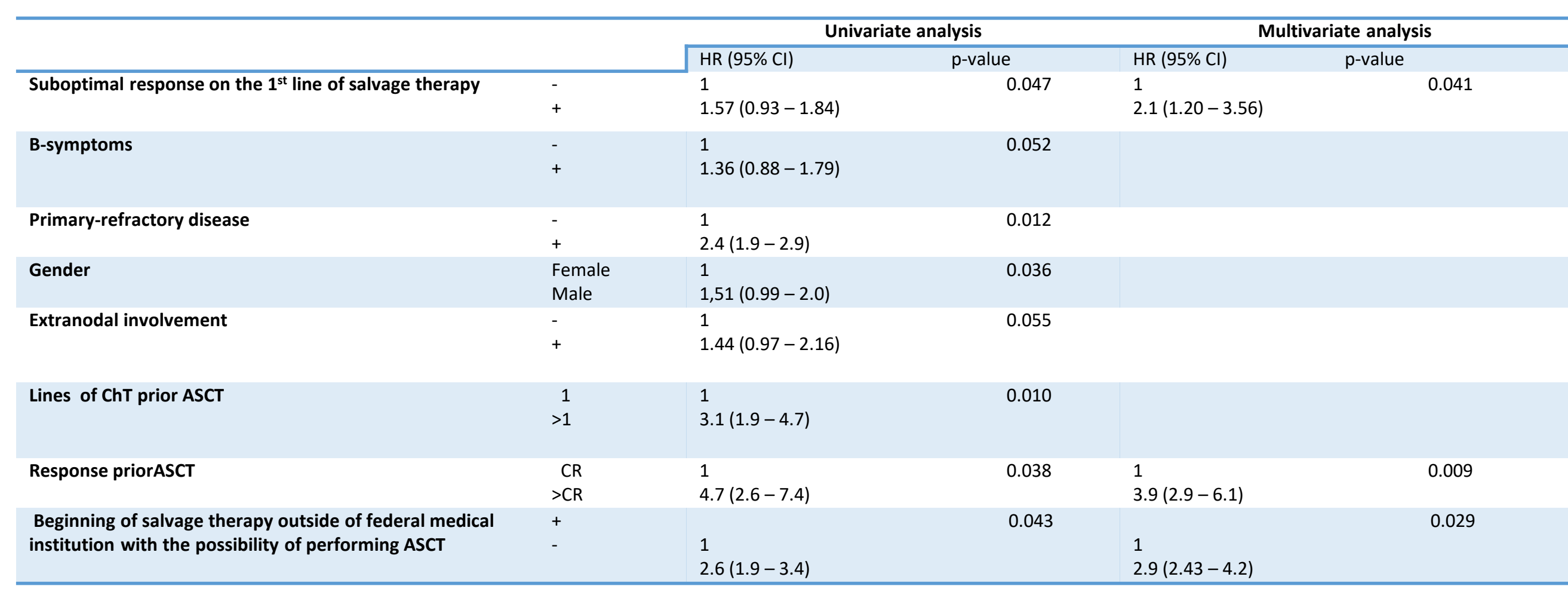

\section{CONCLUSION}

Our results demonstrate that timely mannered qualified medical care is a key component that improves the PFS of patients with relapses and refractory forms of Hodgkin's lymphoma and lack of it is an independent negative prognostic factor together with already studied risk factors.

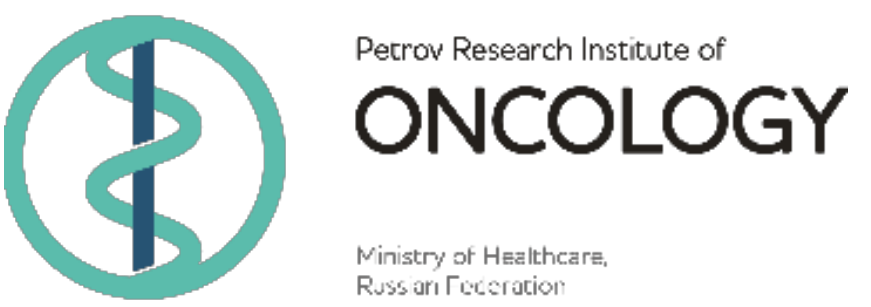

